\title{
Health Information Exchange for Continuity of Maternal and Neonatal Care Supporting: A Proof-of-Concept Based on ISO Standard
}

\author{
M.R. Santos ${ }^{1} \quad$ T.Q.V. de Sá ${ }^{1} \quad$ F.E. da Silva ${ }^{2} \quad$ M.R. dos Santos Junior ${ }^{1} \quad$ T.A. Maia ${ }^{3} \quad$ Z.S.N. Reis ${ }^{1}$ \\ ${ }^{1}$ Universidade Federal de Minas Gerais, Belo Horizonte, \\ Minas Gerais, Brazil \\ 2 Empresa de Informática e Informação do Município de Belo \\ Horizonte S.A., Prodabel, Belo Horizonte, Minas Gerais, Brazil \\ ${ }^{3}$ Secretaria de Estado de Saúde de Minas Gerais, SES/MG, Belo \\ Address for correspondence Z.S.N. Reis, PhD, Centro de Informática \\ em Saúde, Universidade Federal de Minas Gerais Faculdade de \\ Medicina, Av. Professor Alfredo Balena N 190 Sala 601 Belo Horizonte \\ Minas Gerais 30130-100, Brazil (e-mail: zilma.medicina@gmail.com).
} Horizonte, Minas Gerais, Brazil

Appl Clin Inform 2017;8:1082-1094.

\section{Abstract}

Keywords

- maternal and neonatal healthcare information system

- health information exchange

- electronic health records and systems

- two-level modeling

- ISO 13606 standard

- openEHR
Background Around the world, people receive care at various institutions; therefore, clinical information is recorded either on paper or distributed on different information systems with reduced capabilities for sharing data. One approach to handling the complex nature of the health information systems and making it interoperable is the two-level modeling, and the ISO 13606 standard is an option to support this model. A regionally governed EHR program in Brazil proposed to use the ISO 13606 standard and archetypes. This program includes an EHR repository for consolidating the longitudinal electronic record of patients' health.

Objective This article aims to present the results and lessons learned from a proof-ofconcept (POC) for integrating the Maternal and Neonatal Healthcare Information System (SISMater) developed by the Federal University of Minas Gerais (UFMG) with the EHR system developed by the Department of Healthcare for the State of Minas Gerais (SES/MG).

Methods The design of the architecture and software development were driven by the content to be exchanged between the SISMater system and the EHR system and the usage of XML transformation to translate an ISO 13606 EHR extract and vice versa. This POC did not include tests related to revision objects according to ISO 13606 reference model.

Results The software architecture and software components required for this $\mathrm{POC}$ were proposed and tested. The EHR system validated the syntax and semantic and persisted the extract in the EHR repository. Complete results can be accessed at https://github.com/pocppsus/repository.

Conclusion The approach for using XML transformations could make easier the process for ISO 13606 noncompliant EMR systems to exchange EHR data with the SES/MG EHR system. received

June 26, 2017

accepted after revision

September 19, 2017 10.4338/ACI-2017-06-RA0106.

ISSN 1869-0327. 


\section{Background and Significance}

\section{Challenges and Relevant Definitions}

Health information technology has brought improvements to patient care. But beyond the medical and personal records, data exchange among electronic systems demands coordinated efforts around information standards and gathering stakeholders. $^{1}$

Throughout life, people receive care at various institutions. Clinical information is recorded either on paper or distributed on different information systems. Often, these systems are not interoperable, which means that these do not have the ability to exchange information with other systems, which would allow the optimization of scarce resources and the resolution of complex problems. ${ }^{2,3}$

The electronic medical record (EMR) is defined as an automated system based on document imaging or a system that has been developed within a medical practice or community health center practitioners in multiple sites where care is provided. ${ }^{1}$ The electronic health record (EHR) is a longitudinal electronic record of patients' health information generated by one or more encounters in any care delivery setting. ${ }^{4}$ In this approach, the register is entered and accessed electronically by health care providers over the person's lifetime. ${ }^{1}$ The EHR automates and streamlines the clinician's workflow. The data sharing or interoperability process for supporting this concept implies an agreement on the structure and meaning of the data being exchanged. One proposal to handle the complex nature of this kind of system is the two-level modeling. According to this approach, a system should be developed based on two models: a generic information model (reference model) and a domain knowledge model, closer to the domain specialist (knowledge model). The ISO 13606 standard is an example of this approach $^{5}$; it is a simplification of the specification proposed by the openEHR Foundation. ${ }^{\mathrm{a}}$

\section{Local Context and EHR Opportunity for the Pregnancy Stage}

In the context of Brazil, the Unified Health System (SUS) coordinates a network of regionalized and hierarchical services, responsible for the promotion, prevention, recovery, and rehabilitation of health. ${ }^{6}$ Although the country has a national program for e-Health that includes actions for developing a national EHR system, there are still several information systems developed by the federal government in place that focus on specific health programs, diseases, or even specific organization requirements rather than taking a patient-centric and interoperable approach. As a result, this setting generates fragmented information. ${ }^{7}$ Regarding pregnancy, the continuity of care throughout prenatal, childbirth, and early infancy is an excellent opportunity to offer a longitudinal register of attention, impacting the quality of

\footnotetext{
a The openEHR approach is a comprehensive open specification for EHR systems originally based on the results of the Good European Healthcare Record (GEHR) project of the European Union in the early 1990s (http://www.openehr.org).
}

assistance and testing semantic models for the longitudinal health record.

The regional EHR program of the Department of Healthcare for the State of Minas Gerais (SES/MG), ${ }^{\text {b Bazil, }}$ adopted the ISO 13606 standard and archetypes. This proposal includes a statewide EHR repository for consolidating the longitudinal electronic record of patients' health information generated in the context of the Family Healthcare Program (FHP). The solution architecture for this EHR system considers that some different electronic medical record (EMR) systems would have authorized access to exchange data with the centralized repository. ${ }^{3,8}$ This means that different vendors or health care organizations need to adjust their EMR systems to exchange data based on ISO 13606 standard. However, this kind of software development could require some interoperability experts and might take a long time. ${ }^{9}$ Thus, it is valuable to create approaches to reduce the effort of these vendors and health care organizations to exchange data with the SES/MG EHR system.

\section{Two-Level Modeling}

The idea of separation between a model of information and a model of knowledge has its origins in previous research within the information science field. ${ }^{10-15}$ These concepts were applied in the health informatics field by certain European projects ${ }^{16-19}$ and subsequently expanded by the openEHR Foundation. ${ }^{20}$ According to the openEHR specification, the two-level modeling (or multilevel modeling) distinguishes between a reference model (information level) that is used to represent the generic properties of health record data and an archetype model (knowledge level) used to represent the specific information that needs to be documented within health records by each clinical domain. ${ }^{21,22}$

The reference model represents the global constraints of the components of an EHR, the manner in which these are aggregated and the data context required to meet legal and ethical requirements, and the provenance (origin) of the data. This approach defines a set of classes that makes up the structural blocks of an EHR, reflecting its stable constraints. For this model to be stable and able to handle any particular clinical domain, it should be complemented by metadata structures reflecting domain-specific constraints that are restricted by the general classes from the reference model. The formalism for the domain-specific constraints is known as archetypes. ${ }^{16}$

Archetypes are formal expressions of a domain content model in the form of declarations of structured constraints based on a reference model. ${ }^{23}$ Generally designed for broad use, these can, however, be specialized to include local particularities and can accommodate any number of languages and terminologies. ${ }^{24}$ Archetype instances conform to a formal model known as archetype model ${ }^{22}$ and usually are represented as serialized objects through the Archetype Definition Language (ADL). ${ }^{25}$ However, restating clinical

\footnotetext{
b Department of Healthcare for the State of Minas Gerais, Brazil (http://www.saude.mg.gov.br/).
} 
data captured during health assistance demands the reuse of legacy formats. A barrier for sharing them can be the high granularity of data when stored in an EHR system. ${ }^{26}$

\section{ISO 13606 Standard}

The ISO 13606 standard focuses on communication between EHR systems. Its reference model (RM) is a simplification of the architecture put forward by the openEHR Foundation, and it is also based on the two-level modeling approach. In this alignment, the main classes of its RM aim to establish an information model to communicate part or the entire EHR of a given patient (EHR extracts), thus preserving the original clinical meaning intended by the author and reflecting the confidentiality of each data as intended by both author and patient. ${ }^{5}$ The RM defines the following hierarchical levels for EHR data organization (containers): EHR_extract: part of the entire EHR of a single object of care; folder: high-level organization of the EHR; composition: clinical care session, encounter, or document; section: clinical headings reflecting the workflow and consultation process; entry: clinical "statements" about observations, evaluations, etc.; cluster: nested multipart data structures; and element: leaf nodes with single data values. -Fig. 1 shows these hierarchical levels.

The domain knowledge for the ISO 13606 standard also can be represented by a set of archetypes. According to part 2 of this standard, an archetype accounts for a set of constraints placed upon the structure of the data present in the reference model.

When this article was in process, a work group from the ISO TC 215 committee was advanced to define a new version for this standard.

\section{SES/MG EHR System Architecture}

The State of Minas Gerais has over 5,000 primary care units distributed among its 853 cities. It is the largest state in the country in terms of number of cities. ${ }^{27,28}$ In 2011, the
Department of Healthcare of this state developed a state wide EHR repository with the objective of consolidating the longitudinal electronic records of patients' health information generated in the context of the FHP. The intention also uses this same EHR solution as a foundation for secondary and tertiary care systems in the future. ${ }^{3,8}$

The EHR solution architecture includes a centralized repository based on ISO 13606 standard. It considers the use of archetypes to represent clinical concepts, establish rules for data sharing, and define a controlled vocabulary and terminologies. Built on a service-oriented architecture (SOA) approach, the EHR solution offers four services: clinical data services, identification/demographic data services, archetype and terminology services. - Fig. 2 illustrates the highlevel architecture and its services.

The clinical services are composed of two methods: one to send data to the EHR repository and another to retrieve data from the EHR repository. The demographic services make available some methods to retrieve a patient's ID in a similar way as a deterministic master patient index.

This POC is relevant for the SES/MG EHR program to provide technical information for vendors and health care organizations on a feasible, optional, and short path for quickly implementing this required interoperability process.

\section{Maternal and Neonatal Health Care Information System}

SISMater is the result of expertise with electronic health systems to support assistance and monitoring of quality of service in high complexity hospitals. It stands out for developing multidisciplinary teams that include health care professionals and information science and computer science professionals, taking into account real scenarios and information needs for the management of clinical and obstetric health care unit governance. ${ }^{29}$ This health information system has been developed using a model-view-controller

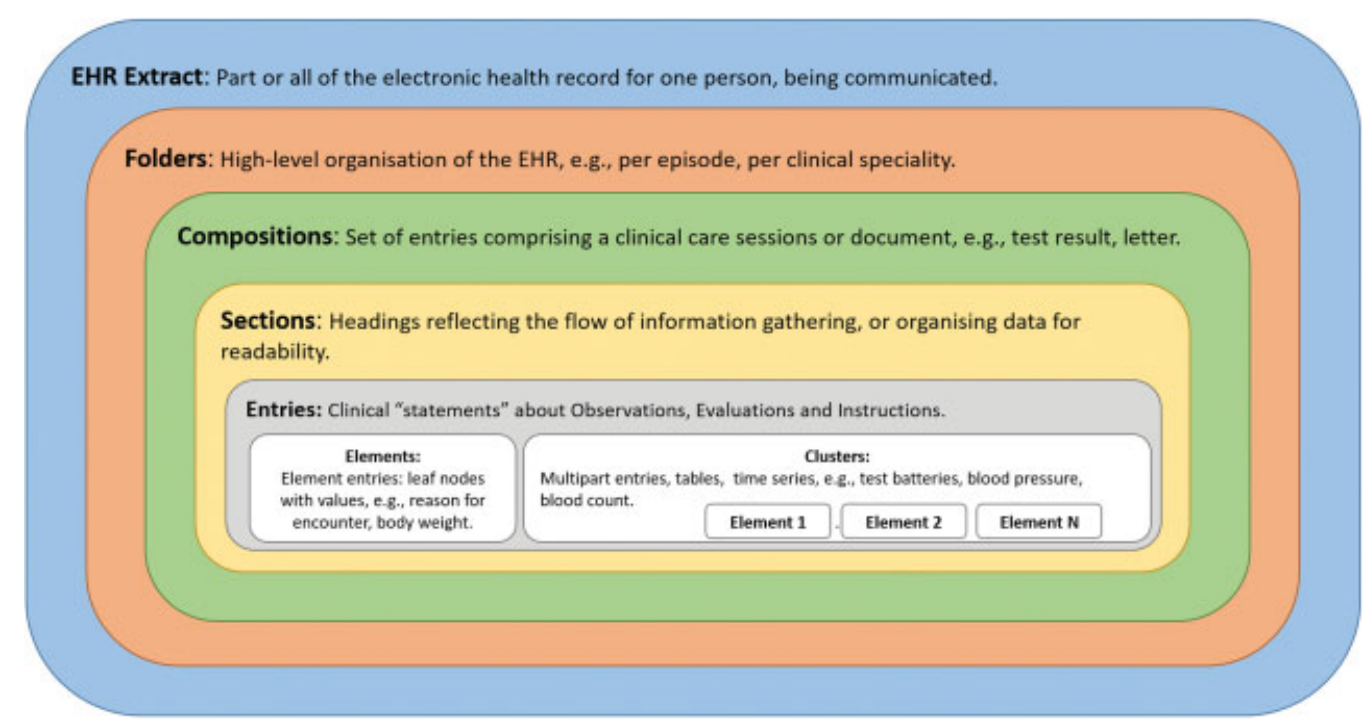

Fig. 1 Reference model building blocks. ${ }^{15}$ 


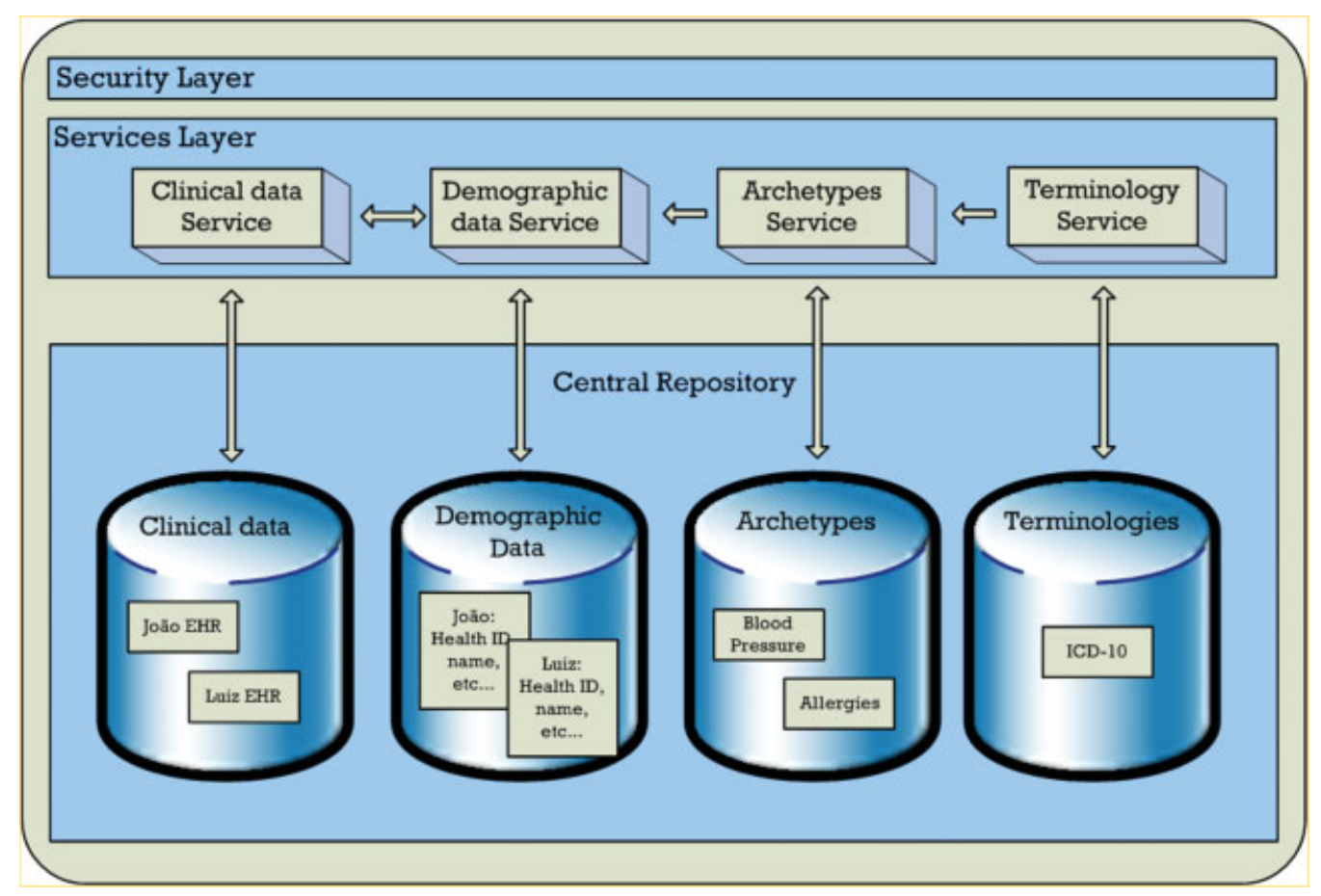

Fig. 2 SES/MG EHR services architecture. ${ }^{16}$ EHR, electronic health record; SES/MG, State of Minas Gerais.

(MVC) approach, PHP for business rules, bootstrap framework and HTML5 for user interface (UI) and MySQL relational database. Health care professionals at the Clinical Hospital of UFMG use it to collect, store, and retrieve clinical information from obstetric admissions to maternity, since 2012, thus generating care quality indicators. ${ }^{30}$ Among its numerous functions, the system produces a discharge report for the mother and the baby. The obstetric inpatient discharge summary (OIDIS) is based on the specifications provided by an information model. ${ }^{31}$

The OIDIS was developed based on frequent clinical concepts used by five Brazilian maternities during the health care transfer between maternities and primary care units. ${ }^{32}$ Brazilian legal recommendations and the SINASC framework ${ }^{33}$ were also considered in this development.

The OIDIS and archetype used can be accessed in documents at https://github.com/pocppsus/repository.

\section{Objective}

This study presents the results and lessons learned from a proof-of-concept for integrating the Maternal and Neonatal Healthcare Information System (SISMater) developed by the Federal University of Minas Gerais with the EHR system developed by the Department of Healthcare for the State of Minas Gerais.

\section{Methods}

This research project was performed in the context of the SES/MG EHR program. A research team from the medicine school of the UFMG, composed by four health informatics and two health care researchers, worked during one year to plan and execute the activities for this project. -Fig. 3 illustrates the functional requirements for this POC. Primary data were captured by physicians in the legacy system using structured interfaces and terminologies. The visualization of standard based medical data had a summary of discharge document format that contained the inpatient obstetric history.

This POC involved selecting the two main kinds of encounters registered at SISMater for testing the data sharing process: Type 1 and Type 2 encounters. Type 1 encounters mean clinical information about the pregnant woman during the maternity stay, while Type 2 is related to the child delivery and neonatal period. It was agreed that the EHR system and SISMater team would create eight fictitious patients with valid SES/MG patient IDs. Storyboards were prepared by domain specialists to give a realistic and varied set of data in the clinical summaries. Existing SISMater capabilities were used for generating obstetric summaries for four Type 1 encounters and four Type 2 encounters, according to the OIDIS (Req no. 1 ). A set of ISO 13606 archetypes representing the summary concepts (composition, sections, entries, elements, and clusters) was developed to support this transformation process. It is important to highlight that part of the OIDIS concepts was already available on the OpenEHR Clinical Knowledge Manager (CKM), ${ }^{34}$ and it was adapted to ISO 13606 archetypes and transferred to the SES/MG archetype repository. ${ }^{35,36}$

These obstetric summaries were to be formalized as XML files (Req no. 2) and translated according to the ISO 13606 reference model, including constraints formalized on the 


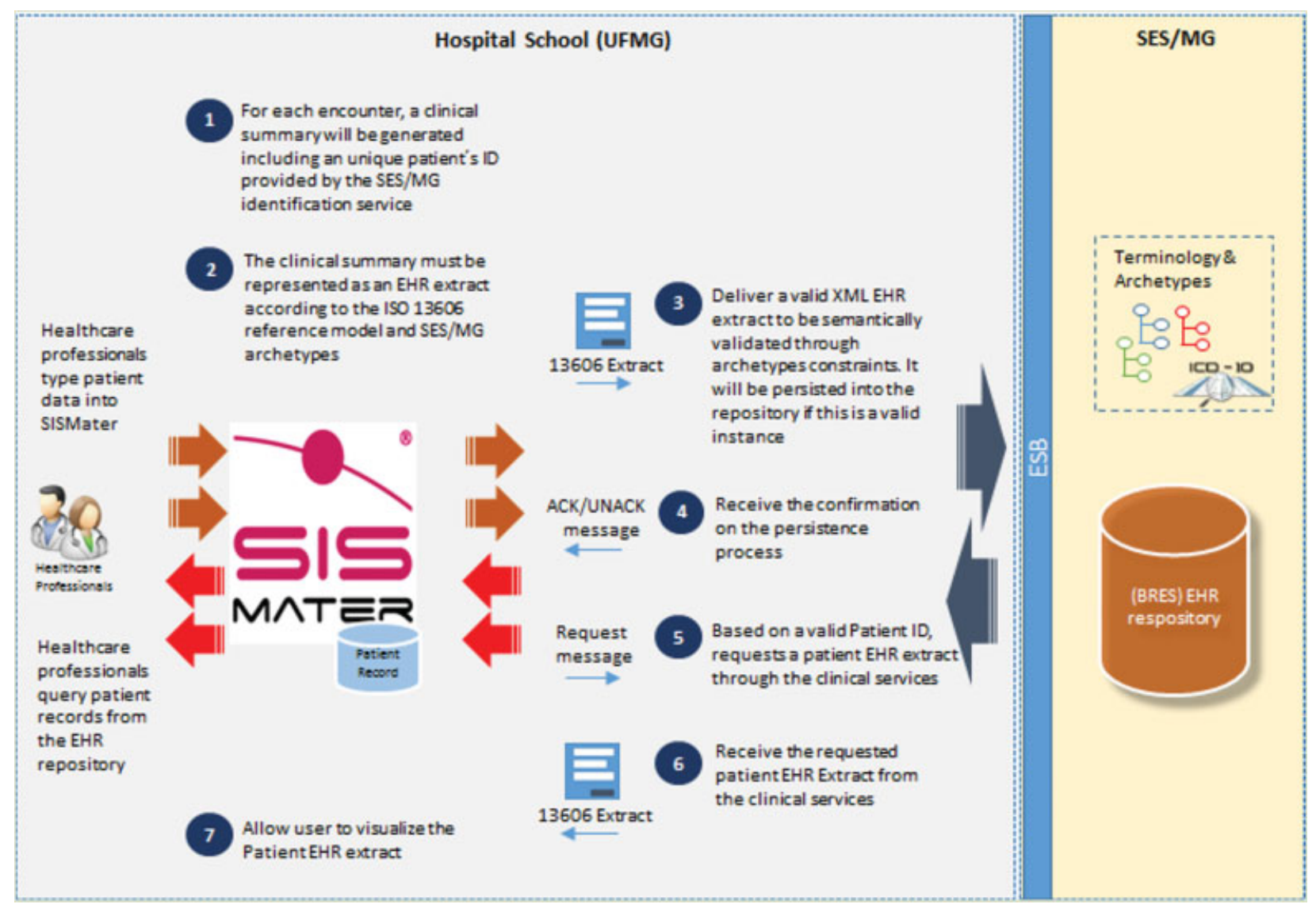

Fig. 3 POC scope. POC, proof-of-concept.

archetypes. As a result, an ISO EHR extract should be delivered (Req no. 3) to the EHR system. The EHR system should receive a valid XML file (EHR extract) and semantically validate it. Finally, the SISMater system should get a confirmation or error log from the EHR system (Req no. 4).

For retrieving EHR extracts from the EHR repository, the SISMater should send a message to the EHR system including a valid patient ID and receive the patient's data as a valid XML file (EHR extract, Req no. 5). After receiving it, SISMater should present this content to end users (Req no. 6). A further requirement (Req no. 7) for this POC includes translating the ISO EHR extract to the SISMater original format.

An important requirement for this $\mathrm{POC}$ is using a simpler XML schema (Req no. 8), including only required fields, hiding some hierarchical and repetitive structures, as vendors would only work with a same EHR repository. The flat XML file was the name used for this simpler XML schema. The idea behind it was to provide an easier way for vendors who do not have knowledge and experience working with ISO 13606 RM and archetypes to quickly implement capabilities for exchanging data with the EHR system. Of course, in a real scenario, some vendors decide using the official ISO13606 instead of this flat XML approach.

As for validation criteria, it was assumed that the approach would generate four patient summaries on SIS-
Mater for each of the two mentioned encounter types, sending it to the EHR system, querying it from the EHR system, and presenting it to end users. The same original data should be visualized by the end users at the end. A group of two users of SISMater worked to check these results.

Regarding technologies choices, the Java components were developed based on JEE 1.7.0_09/JDK 1.7.0_09, XML transformations for generating new XML representations through XQuery, ${ }^{37}$ syntactically validating XML files through XML schema definition (XSD), and allowing a standardized visualization of the patient's record based on eXtensible Stylesheet Language Transformations (XSLT). ${ }^{38}$ Furthermore, an API of the EHR system was used for syntactic and semantic validation of the EHR extracts.

In addition, a RESTful API was adopted for processing XQuery and generating XSD schemas. A translation layer based on this technology allowed the required low technological coupling and flexibility to adapt the code for simulating different scenarios. This decision aimed to enable the development of reusable and extensible software agents that could easily be hosted and made accessible for other software applications.

All XQuery and XSLT scripts, Java and ADL codes developed during this project are available on the following URL: https://github.com/pocppsus/repository. 


\section{Results}

This section describes the software architecture developed to meet the requirements for this POC. - Fig. 4 illustrates the high-level view for the three main layers of this architecture.

The EHR system layer is an abstraction of the services offered by the SES/MG EHR system (see Section 1.4). As illustrated in -Fig. 4, this POC considered the clinical services, demographic services, and identity and access management (IAM) services from the EHR system architecture. The terminology and archetype services were still under development when this POC was being completed. The SISMater platform layer is a representation of the main SISMater components considered for this software solution. The SISMater integration manager is responsible for orchestrating transactions to achieve the interoperability objectives. The document viewer is responsible for presenting EHR extracts to authorized end users, according to SES/MG security and confidentiality policy. Finally, the translation layer includes the following components.

1. ModelGenerator: When a new version of archetype is created or updated by SES/MG health care domain experts, an administrative user of the EHR system must generate a new XML flat model. In this alignment, the ModelGenerator component includes different classes responsible for dynamically generating the XML flat, XML schemas, and XQueries reflecting constraints formalized in a set of archetypes. See - Supplementary Appendix A, available in the online version.

2. XSDGenerator: New XSD schemas are required to compose a new XML flat model. The XSDGenerator component is responsible for generating the XML schema for the new XML flat file. See - Supplementary Appendix B, available in the online version.

3. ExtractConversor: When sending data to the EHR system, this component is responsible for receiving a XML flat file from the SISMater integration manager (requestor component), generating XQuery scripts, applying them to translate the XML flat file to an ISO 13606 EHR extract, and returning this EHR extract for the requestor component (Req no. 3, see -Supplementary Appendix C, available in the online version).

4. XMLFlatConversor: This component is responsible for receiving an ISO 13606 EHR extract from the EHR system, generating XQuery scripts, applying it to translate the extract to a XML flat file, and returning it for the requestor component (Req no. 5, see - Supplementary Appendix D, available in the online version).

-Fig. 5 illustrates how these components interact with each other for sending data from the SISMater system to the EHR system.

A clinician confirms sending encounter data to the EHR system, and a SISMater procedure generates an OIDIS according to the classes of the XML flat XSD schema (Req no. 2). The

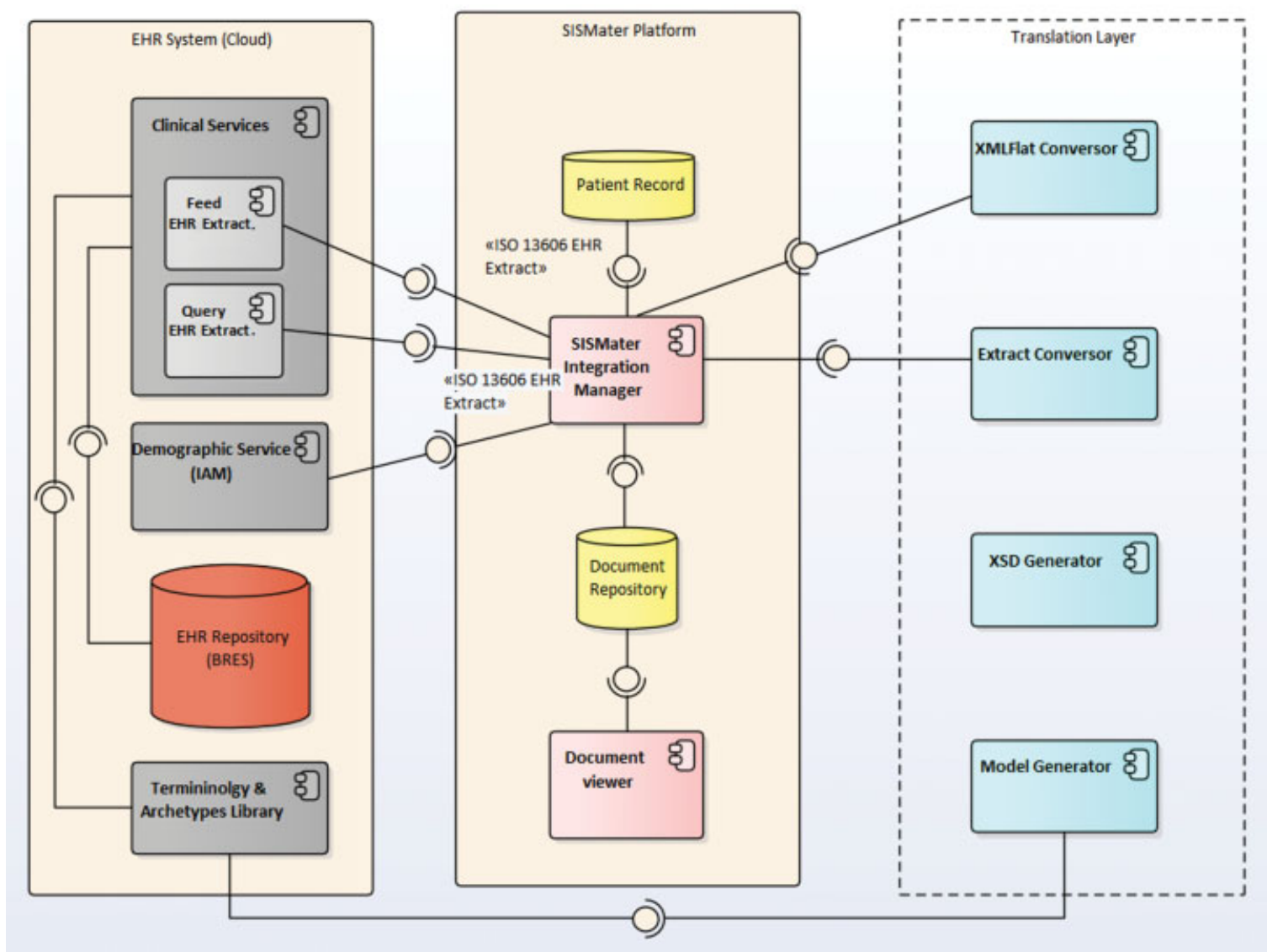

Fig. 4 High-level components diagram. 


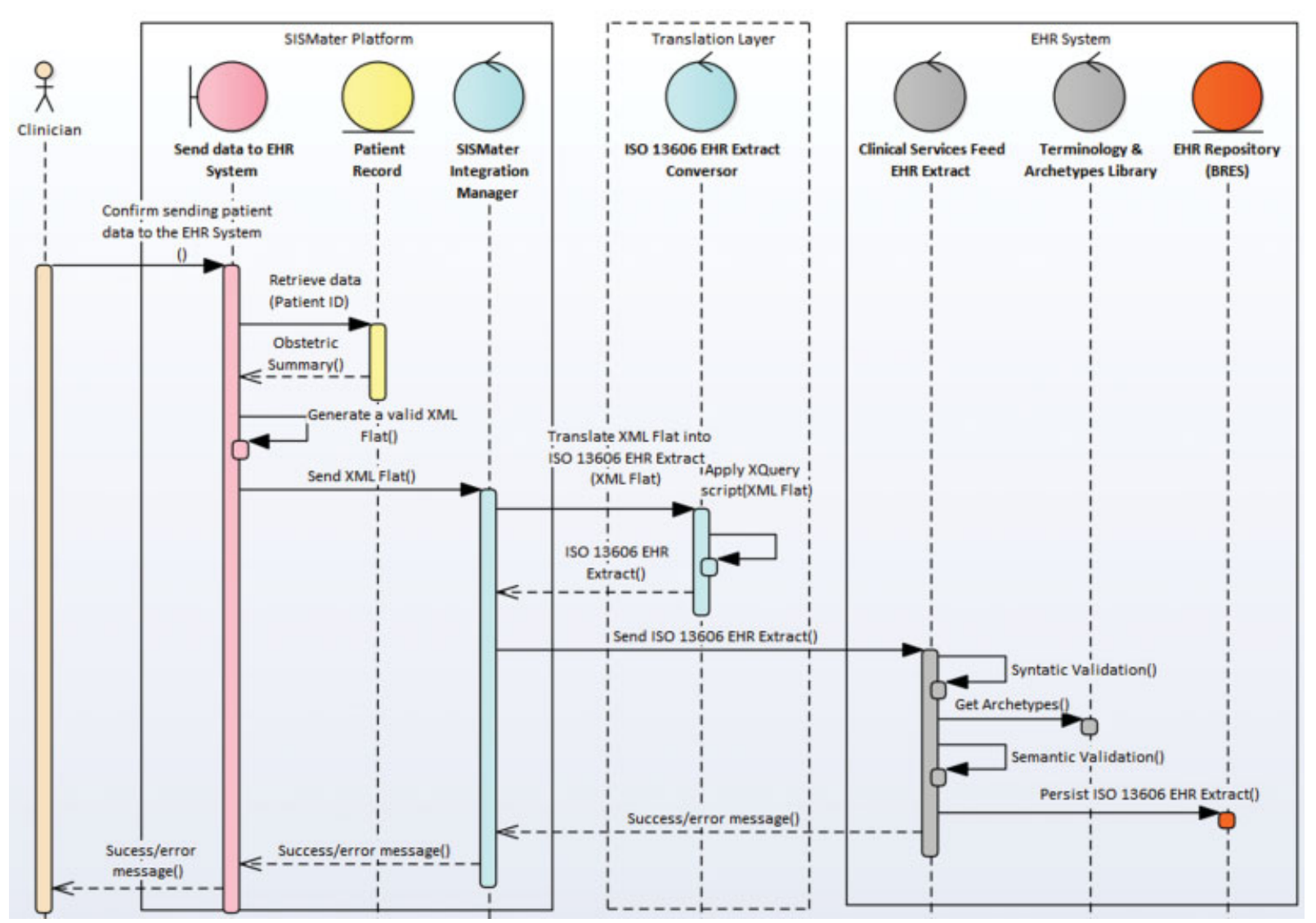

Fig. 5 Sequence diagram for sending data to the EHR system. EHR, electronic health record.

SISMater integration manager calls the ExtractConversor component to translate this generated XML flat to an ISO 13606 EHR extract (through an XQuery script) and sends it to the EHR system (Req no. 3). The clinical services of the EHR system validate the syntax and semantic before sending the extract to the EHR repository. Finally, a success or error message is sent back to the SISMater system (Req no. 4). It is important to highlight that (1) the archetypes and code systems were copied from the EHR system to the SISMater platform because the terminology and archetypes services were not available; and (2) the process to get a valid patient ID from the master patient index of the EHR system (Req no. 1) was performed during the patient admission process. - Fig. 6 illustrates the process for retrieving data from the EHR system.

A clinician could use the global patient ID to search existing ISO 13606 EHR extracts on the EHR system (Req no. 5). The clinician could opt for one of the three options: (1) to persist the resulting EHR extract in the SISMater document repository, exactly as it comes from the EHR system; (2) visualize the resulting EHR extract as it comes from the EHR system based on XSLT transformation (Req no. 6); or (3) persisting data resulting from the EHR extract to the SISMater patient record (Req no. 7). However, only the option "2" was implemented for this POC. See the XSLT scripts used in the context of the document viewer implementation in - Supplementary Appendix E, available in the online version.

As mentioned, the XML flat model is an important concept for this POC (Req no. 8). It is composed of simpler classes reflecting the ISO $13606 \mathrm{RM}$ and archetypes. In practice, the flat XML file is smaller because some of the constraints and ISO 13606 RM classes/attributes are included on the XQuery scripts. As the POC described has focus on the data exchange for a specific unified regional EHR repository, repeated definitions for describing EHR extract contextual information (e.g., for OIDs, code systems, archetype codes, datatypes, etc.) and hierarchical structures definitions (e.g., entries, clusters, elements, etc.) could be captured through XML transformations rules. The transformation of this flat XML file to ISO 13606 EHR extract and vice versa are performed via XQuery scripts. See the XQuery scripts in Appendices C and D. - Fig. 7 illustrates an excerpt of an ISO 13606 EHR extract and the corresponding flat XML representation.

-Fig. 8 illustrates an excerpt of an XQuery script to generate the ISO 13606 EHR extract (illustrated in - Fig. 7) from the flat XML file. Observe that in this example, because we were generating an ISO 13606 EHR extract, a new rc_id was being created. However, when receiving these extracts from the EHR system, the existing UUIDs must be kept. Rc_id means the globally-unique identifier by which the instance of a RECORD_COMPONENT is referenced in the EHR system to which the data were first committed.

According to the methods proposed for this POC, eight patient summaries covering two defined types of encounters were created on SISMater system. These summaries were translated to ISO 13606 EHR extracts and sent to the 


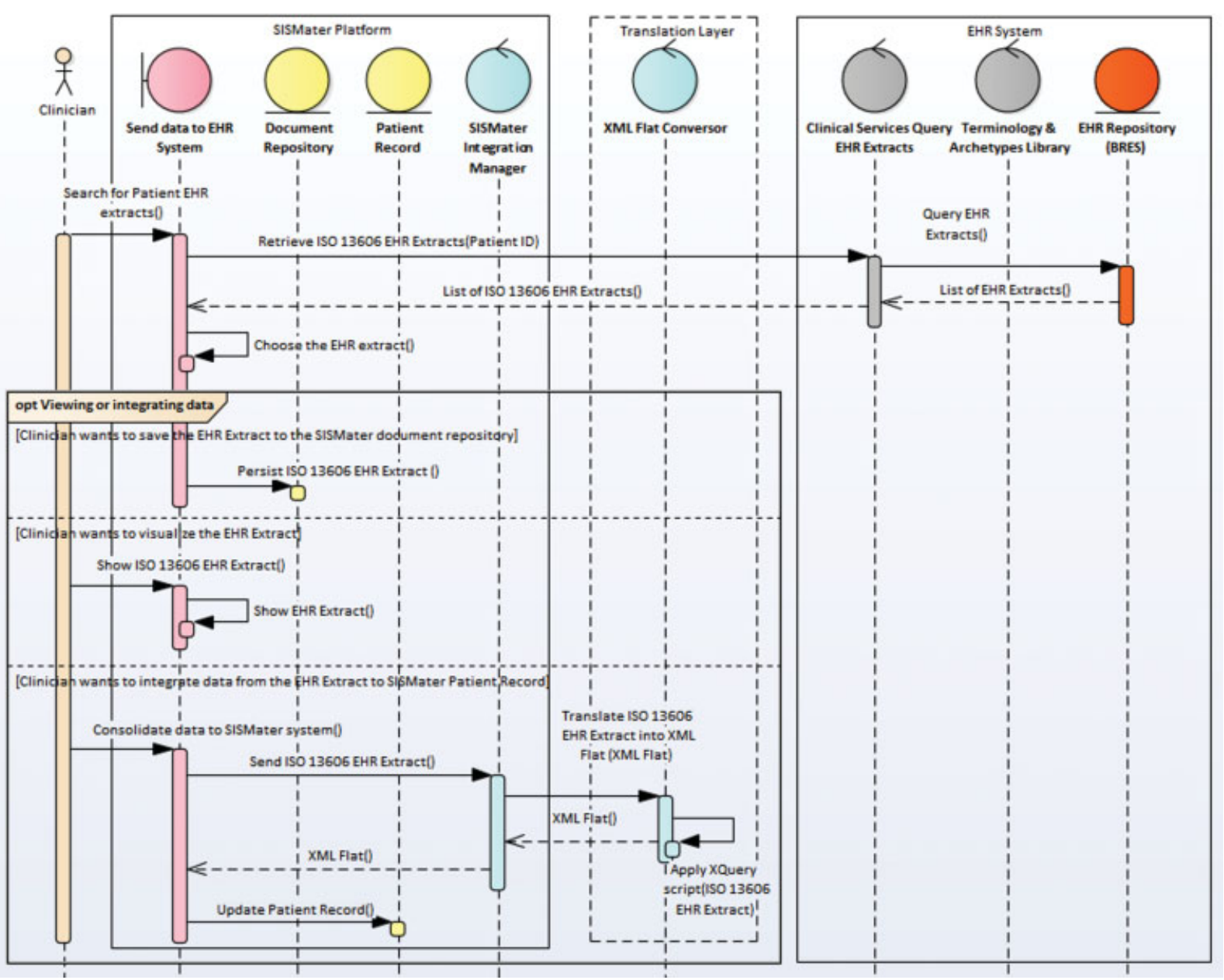

Fig. 6 Sequence diagram for retrieving data from the EHR system. EHR, electronic health record.

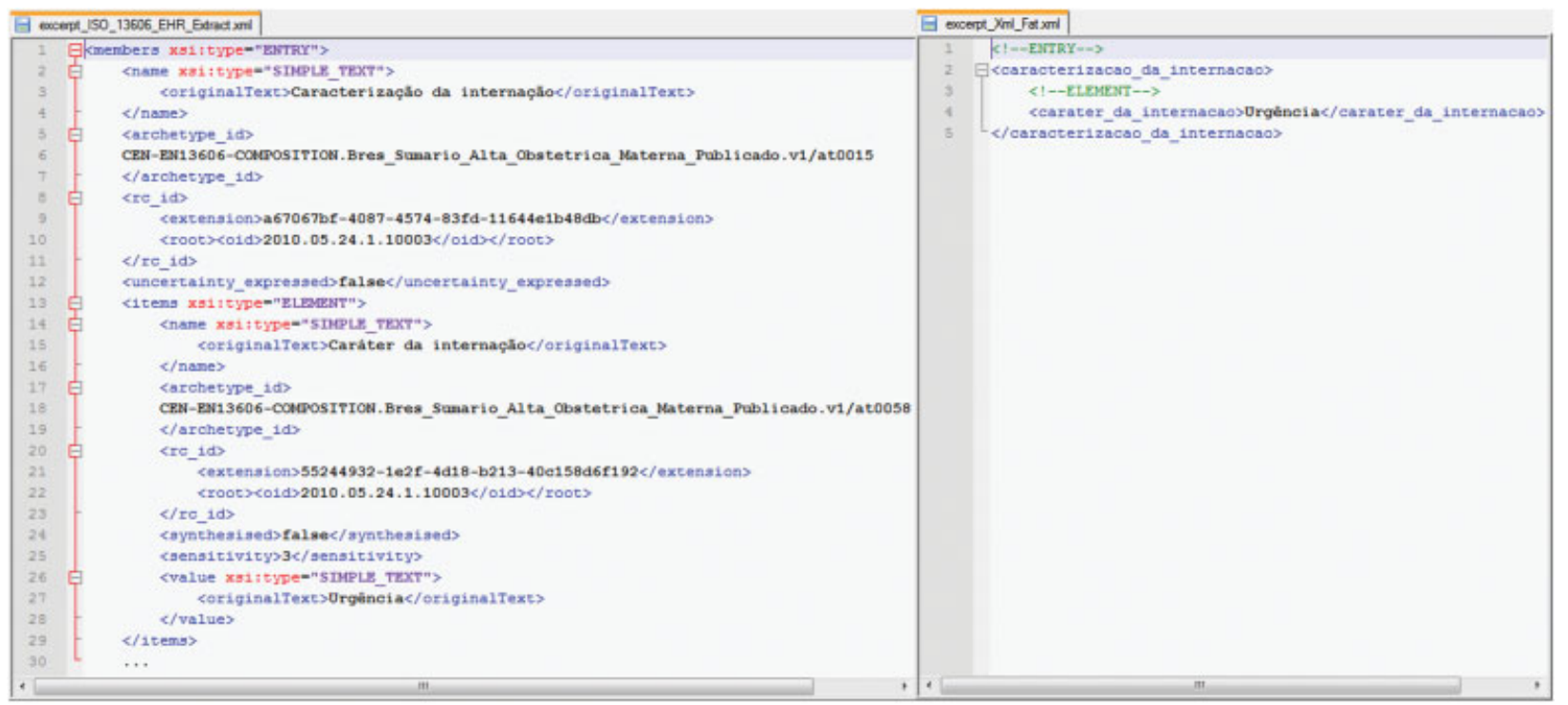

Fig. 7 An excerpt of an ISO 13606 EHR extract and the corresponding XML flat representation. EHR, electronic health record. 


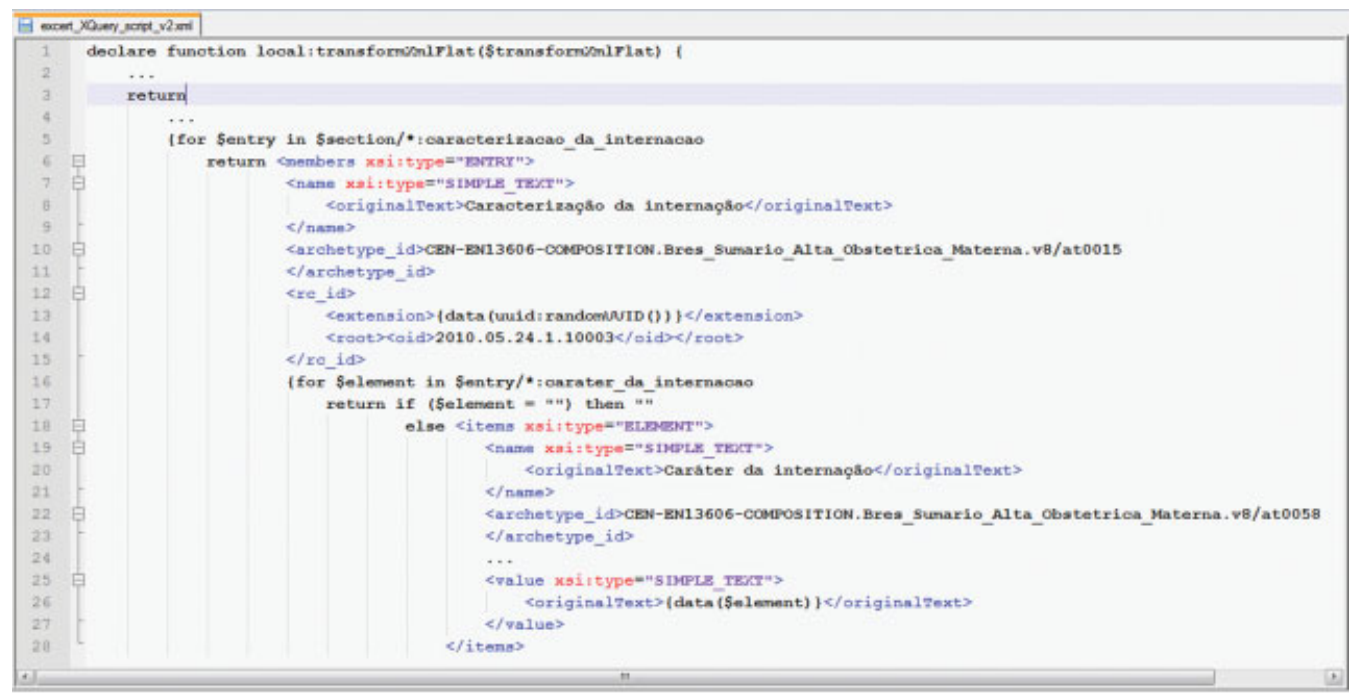

Fig. 8 XQuery, including constraints, classes, and attributes of ISO 13606 RM. RM, reference model.

SES/MG EHR system. In the end, these EHR extracts were queried and presented to end users with no evidence of content errors.

\section{Discussion}

Currently, we presented a POC for integration of archetypes in legacy EMR system and a centralized repository based on ISO 13606 standard. The approach was able to successfully integrate summaries from the maternity hospital to the Government EHR system. The XML flat model is an important concept for this proposed architecture. The design of this model was driven by the content to be exchanged between the SISMater system and the EHR system and the usage of XML transformations to translate ISO 13606 EHR extract and vice versa. Based on a set of archetypes, the components were able to generate the required XQuery scripts and XML schema for the XML flat file. The XQuery scripts automatically generated were able to produce EHR extracts from existing XML flat files and vice versa, covering all clinical concepts of the OIDIS.

The main lesson learned from this experiment was related to the adjustments for making the SISMater system able to exchange data with the EHR system. The ExtractConversor and XMLFlatConversor components made it easier to implement the interoperability transactions. To adapt the SISMater system, it was only necessary to understand the structure of the XML flat schema and develop capabilities for the SISMater integration manager to these two components. Of course, some time was spent correlating the SISMater code systems to those code systems defined in the XML flat model. As explained in previous sections, some details behind the use of the ISO $13606 \mathrm{RM}$ and archetypes themselves were hidden to developers (see Appendices B and C), who focused on the development of the transactions for exchanging data according to the XML flat schema. After developing the APIs and making it available, the complete integration for sending and receiving data, including tests, was developed in 1 week by a developer not experienced with ISO 13606.
The complete architecture created for this POC was described in Section 4 and Appendices and all XQuery and XSLT scripts, Java and ADL codes developed during this project are available on the following URL: https://github.com/pocppsus/repository.

The Department of Healthcare for the State of Minas Gerais adopted the ISO 13606 standard due to the flexibility provided by its archetypes model for supporting health care experts in representing clinical concepts. Thus, the archetypes library is supposed to be updated many times to cover new concepts and/or changes on existing concepts from the health care domain. In addition, it is essential to keep noncompliant ISO 13606 EMR vendors informed about these changes.

The EHR system administration team could use the components to efficiently generate new XQuery scripts and XML schema for reflecting a new set of archetypes, reinforcing the current policy in place on SES/MG. However, this POC only covered transactions to allow SISMater to exchange data with the SES/MG unified EHR repository. In this sense, it does not cover all diversity of possibilities that can be achieved by using ISO 13606 EHR extract classes and archetypes definitions. It is still recommended that these components could be tested to ensure their accuracy for other kinds of data and clinical scenarios.

This POC did not include tests related to revision objects according to ISO 13606 RM. Because the AUDIT_INFO class and attributes were modeled as part of the XML flat model, the revision transactions (draft instance, corrections, logical deletion) are presumed to be covered for this implementation. However, more specific tests need to be performed on this point.

Countries at different stages of development and socioeconomic conditions use information technology (IT) in the health care context according to the planning and investment in this area. ${ }^{39}$ In maternal-infant care scenario, a ceaseless flow of information is required. But to ensure the interoperability of information systems to support the 


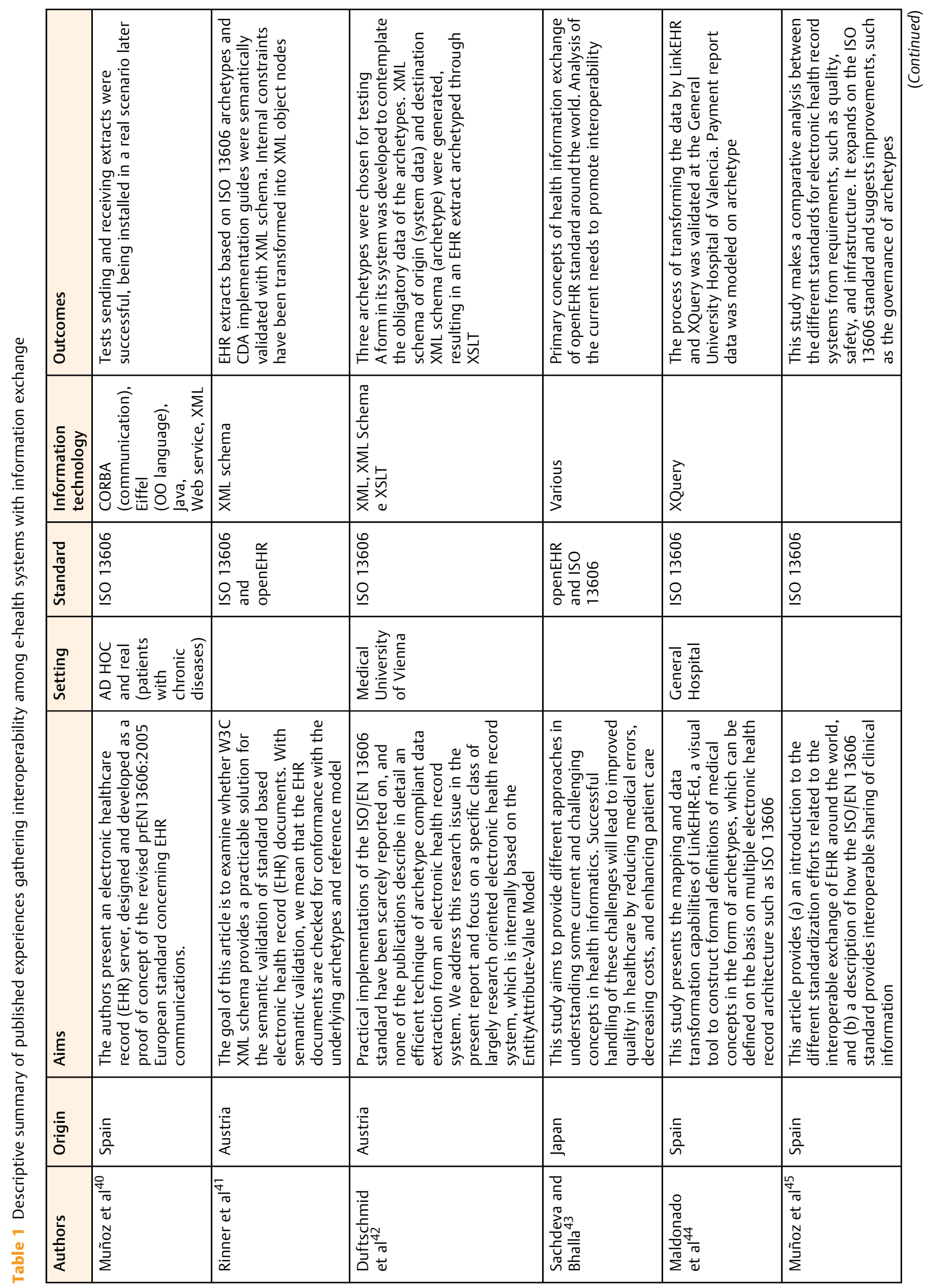




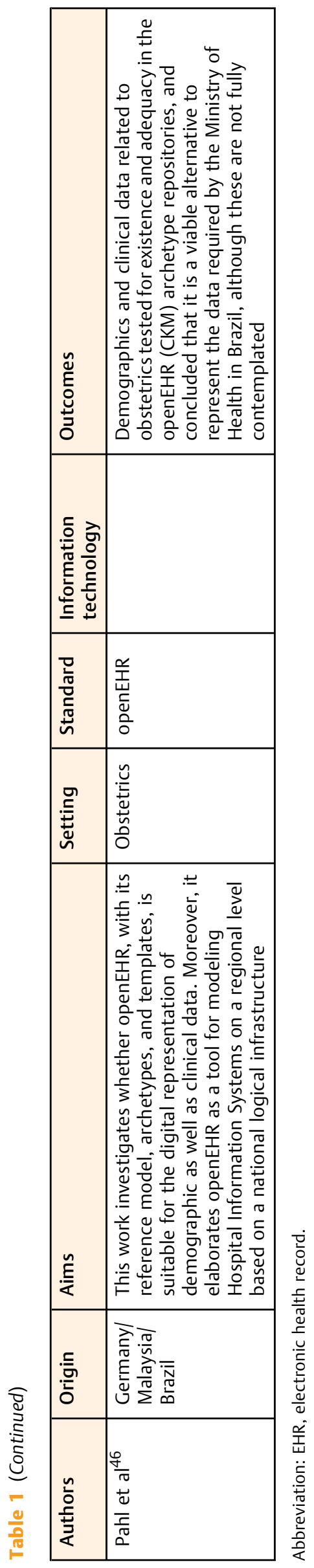

health care process, stakeholders need frameworks based on standardizing health data. In South America, recognizing the importance of standardizing data and its relevance for ehealth systems and services, Pan American Health Organization works to establish standards on health data at the national and subnational levels and guarantee the confidentiality of personal clinical information. ${ }^{1}$ The present POC is the result of the academy's and government's efforts in this challenge.

Previously published experiences that contributed to the cross organizational semantic interoperable communication of EHR data based on two-level modeling are presented in -Table 1.

A POC tested the application of ISO 13606 for health information exchange and its performance in various server configurations. ${ }^{40}$ The experience was applied in a real scenario with effectiveness in promoting the exchange of health information. Similarly, to the present analysis, the two-level modeling proposed by ISO 13606 was the solution that represented the clinical concepts. An advantage found by Munoz et $\mathrm{al}^{40}$ was the possibility of adapting the information system to the evolution of concepts in health, which are generally complex and vulnerable. Considering the future evolution of this proof-of-concept about birth data for a real scenario, it was highlighted the importance of an interoperability solution feasible for users who do not have prior knowledge of ISO 13606. Therefore, XML flat used in the process of sending and receiving information was relevant to democratize the present experience and allow its expansion. This principle was also adopted by Rinner et $\mathrm{al}^{41}$ when choosing syntactic and semantic validation by XML schema, since it is a better known technology, instead of validation by archetypes.

Similar approach for transforming data from an electronic health record system to an EHR extract by ISO 13606 is based on entity-attribute-value, forms with the mandatory attributes of the archetypes were developed. Schemas of archetypes and forms have been extracted. ${ }^{42}$ With the help of the XSLT language, it was possible to construct a RES extract compatible with the archetypes.

Sachdeva and Bhalla compared the query language of the openEHR standard, known as AQL (Archetype Query Language), with other languages (XQuery, SQL, OQL). In that experience, XQuery was chosen to transform XML flat into an EHR extract, a standard language recommended by W3C and supported by most databases. ${ }^{43}$

LinkEHR is a known tool for manipulating ISO 13606 archetypes and allows the manipulation of heterogeneous data sources with support of the XQuery language. It was tested at the General University Hospital of Valencia and obtained good results in the mapping of information between systems at a structural and conceptual level. ${ }^{44}$

The ISO 13606 standard needs to evolve toward its usage as a central repository, valuing the reuse and standardization of archetypes around the world. ${ }^{45}$ On the other hand, the openEHR standard is evidenced by the extensive repository of published archetypes, available for use, adaptation, and continuity of clinical concepts known as CKM. ${ }^{34}$ 
Previous experience reported in Brazil had an objective to find and adapt archetypes required to represent the obstetric data required by a health service. ${ }^{46}$ The study highlighted the complexity in modeling obstetric data, considering the variations in obstetric care for different regions of the country, and peculiar obstetrics characteristics that go beyond the usual models for electronic medical records. ${ }^{46}$

\section{Conclusion}

This POC's results showed a feasible approach based on XML transformations to make ISO 13606 noncompliant EMR systems able to exchange data with the SES/MG EHR system. It was realized that the required effort for adapting SISMater system could be reduced using this approach. Because the technologies discussed on this article are stable and known to the IT market, it is possible that even those EMR vendors that do not know about ISO 13606 concepts could readily adapt their systems to exchange data with the SES/MG EHR system.

\section{Clinical Relevance Statement}

The information exchange between systems has the potential to improve the quality of care and contribute to a comprehensive and continuous assistance. This POC represents efforts to reduce the fragmentation of information between unintegrated systems and ensure interoperability based on standards. Even if this conceptual model has success, to achieve a new scenario, governmental efforts are still necessary to support the real implementation.

\section{Multiple Choice Question}

A government interested to create a regional EHR system could use some strategies to reduce the learning curve for new EMR vendors adapting your systems to exchange documents based on interoperability standards. Which of the options below is an effective and feasible action to reduce the learning curve for using interoperability standards?

A. Make available for new EMR vendors simplified data schemes, XML transformation artifacts, restful APIs, and well-defined implementation guide

B. To exchange data to the regional EHR system, only accept EMR software developed by very experienced EMR vendors

C. The government assumes responsibility to adapt all vendor EMR systems and use its own software team to do it

D. To exchange data to the regional EHR system, only accept data coming from EMR systems developed by the government

Correct Answer: The correct answer is A. The use of interoperability standards in healthcare increases the quality of information for the context of delivering services for the healthcare continuum. However, usually, the learning curve to implement a document-sharing process based on interoperability standards is steep.
Protection of Human and Animal Subjects

The authors declare that human and animal subjects were not included in this research.

\section{Funding}

This study was supported by Fundação de Amparo à Pesquisa de Minas Gerais (FAPEMIG)-PPSUS APQ 03486-13.

Conflict of Interest

None.

\section{References}

1 Pan American Health Organization. eHealth in Latin America and the Caribbean: interoperability standards review. 2016. Available at: http://iris.paho.org/xmlui/bitstream/handle/123456789/28189/ 9789275118818_eng.pdf? sequence=1\&isAllowed=y

2 Mendes EV. As redes de Atenção à Saúde. Ciência e Saúde Coletiva. Rio de Janeiro 2010;15(05):2297-2305

3 dos Santos MR. Sistema de registro eletrônico de saúde baseado na norma ISO 13606: aplicações na Secretaria de Estado de Saúde de Minas Gerais. Perspectivas em Ciência da Informação. Belo Horizonte 2011:272-272

4 Healthcare Information and Management Systems Society (HIMSS). Electronic Health Records. Available at: http://www. himss.org/library/ehr

5 International Organization for Standardization. ISO 136061:2008:Health informatics, Electronic health record communication, Part 1: Reference model. 2008

6 Brasil. Lei ${ }^{\circ}{ }^{\circ} 8.080$, de 19 de setembro de 1990: Dispõe sobre as condições para a promoção, proteção e recuperação da saúde, a organização eo funcionamento dos serviços correspondentes e dá outras providências. Diário Oficial da União 1990. Available at http://www.planalto.gov.br/ccivil_03/leis/L8080.htm

7 Brasil. Estratégia e-Saúde para o Brasil. Diário Oficial da União. Brasília: Ministério da Saúde Departamento de Informática do SUS, Secretária de Gestão Estratégica e Participativa; 2014

8 Maia TA. Processo de Desenvolvimento de Arquétipos do Registro Eletrônico em Saúde em Minas Gerais: Estudo de Caso. Projetos e Dissertações em Sistemas de Informação e Gestão do Conhecimento. 2015;3 Available at: http://www.fumec.br/revistas/sigc/ article/view/2685. Accessed June 1, 2016

9 Benson T. Principles of health interoperability HL7 and SNOMED. London: Springer Science \& Business Media; 2012:316

10 Newell A. The knowledge level. Artif Intell 1982;18:87-127

11 Gruber TR. A translation approach to portable ontology specifications. Knowl Acquis 1993;5(02):199-220

12 Guarino N. Formal ontology, conceptual analysis and knowledge representation. Int J Hum Comput Stud 1995;43:625-640

13 Guarino N, Giaretta P. Ontologies and knowledge bases: Towards a terminological clarification. Towards very large knowledge bases: knowledge building and knowledge sharing. 1995;25;32

14 Johnson SB. Generic data modeling for clinical repositories. J Am Med Inform Assoc 1996;3(05):328-339

15 Chandrasekaran B, Josephson JR, Benjamins VR. The ontology of tasks and methods 1999:31-43. Available at: http://ksi.cpsc. ucalgary.ca/KAW/KAW98/chandra/. Accessed February 3, 2016

16 Kalra D. Electronic health record standards. Germany: Schattauer GMBH-Verlag; 2006. Available at: http://www.schattauer.de/en/ magazine/subject-areas/journals-a-z/imia-yearbook/imia-yearbook-2006/issue/special/manuscript/6382/show.html. Accessed February 3, 2016

17 Kalra D. The SYNAPSES project: Current Perspectives in Healthcare Computing Conference. Harrogate, England: BJHC LTD; 1997. Available at: http://discovery.ucl.ac.uk/66281/. Accessed February 3, 2016 
18 Grimson J, Grimson W, Berry D, et al. A CORBA-based integration of distributed electronic healthcare records using the synapses approach. IEEE Transactions on Information Technology in Biomedicine 1998; 2(03):124-138. Available at: http://ieeexplore.ieee.org/ielx5/4233/ 15835/00735777.pdf?tp=\&arnumber=735777\&isnumber=15835. Accessed February 3, 2016

19 Bird L, Goodchild A, Tun ZZ. Experiences with a two-level modelling approach to electronic health records. J Res Pract Inf Technol 2003;35:121-138

20 OpenEHR. Design Principles. Available at: http://www.openehr. org/releases/1.0.1/html/architecture/overview/Output/design_ principles.html

21 Michelsen L, Pedersen SS, Tilma HB, Andersen SK. Comparing different approaches to two-level modelling of electronic health records. Studies in Health Technology and Informatics. Amsterdam; Washington, DC: IOS Press; 19912005:113-118

22 Beale T, Heard S. Archetype Definitions and Principles. Release 1.0. 1. 2007:15. Available at: http://www.openehr.org/releases/1.0.2/ architecture/am/archetype_principles.pdf. Accessed February 3, 2016

23 Beale T, Heard S. Architecture Overview. The OpenEHR Foundation. Available at: http://www.openehr.org/releases/1.0.1/architecture/overview.pdf

24 Buck J, Garde S, Kohl CD, Knaup-Gregori P. Towards a comprehensive electronic patient record to support an innovative individual care concept for premature infants using the openEHR approach. Int J Med Inform 2009;78(08):521-531

25 Beale T, Heard S. Archetype Definition Language. The OpenEHR Foundation. 2007:115. Available at: http://www.openehr.org/releases/1.0.1/architecture/am/adl.pdf. February 3, 2016

26 Marco-Ruiz L, Moner D, Maldonado JA, Kolstrup N, Bellika JG. Archetype-based data warehouse environment to enable the reuse of electronic health record data. Int J Med Inform 2015; 84(09):702-714

27 Brasil, CNESNet. Consulta Estabelecimentos de Minas Gerais. Available at: http://cnes.datasus.gov.br/. Accessed May 18, 2016

28 Brasil. Número de municípios nos Censos Demográficos, segundo as Grandes Regiões e as Unidades da Federação-1960/2010. Instituto Brasileiro de Geografia e Estatística. Available at: http://www. censo2010.ibge.gov.br/sinopse/. Accessed February 15, 2016

29 Gaspar J, Chagas J, Cruz-Correa R, Reis SN. Health information system for obstetric and neonatal healthcare monitoring: SISMater. Paper presented at: 8th Iberian Conference; June 19-22, 2013; Lisboa, Portugal. Available at: http://ieeexplore.ieee.org/ document/6615808/

30 Gaspar Jde S, Reis ZSN, Gusmao RR, Sá TQV de. Improving health care access using geographic information systems: SISMater-GIS: a study of referencing for childbirth in a university maternity in Belo Horizonte, Brazil. Paper presented at: IEEE 27th International Symposium; May 27-29, 2014; New York, NY. Available at: http://ieeexplore.ieee.org/document/6881939/

31 Reis ZSN, dos Santos Junior MR, Gaspar Jde S, Maia TA, de Souza AC, Santos MR dos. Electronic systems interoperability study: based on the interchange of hospital obstetrical information. Paper presented at: IEEE 28th International Symposium;
June 22-25, 2015; Sao Carlos, Brazil. Available at: http://ieeexplore.ieee.org/document/7167486

32 Reis ZSN, de Aguiar RALP, Ferreira ÁAT, Viegas AC, Anchieta LM. Análise do conteúdo do sumário de alta obstétrica em maternidade de referência Uma oportunidade para repensar a estratégia da continuidade do cuidado materno e neonatal. Rev méd Minas Gerais. 2015;25(4)

33 Fundação Nacional de Saúde. Manual de instruções para o preenchimento da declaração de nascido vivo. Fundação Nacional de Saúde Brasília; 2001. Available at: http://bvsms.saude.gov.br/bvs/ publicacoes/funasa/declaracao_nasc_vivo.pdf. Accessed February 3, 2016

34 OpenEHR. Clinical Knowledge Manager. Available at: http:// www.openehr.org/ckm/. Accessed February 3, 2016

35 Santos MR, Bax MP, Kalra D. Dealing with the archetypes development process for a regional EHR system. Appl Clin Inform 2012; 3(03):258-275

36 Ferreira AAT, Reis ZSN, Frade S, Gaspar JS, Correia RJC, Hadad SC, et al. Proposição de um sumário de alta obstétrico visando à troca de informações, em padrão OpenEHR, para continuidade do cuidado materno-infantil. Rev Fac Med Ribeirão Preto Hosp Clín FMRP Univ São Paulo 2014;47(01):59-66

37 W3C. XQuery 1.0: An XML query language (second edition). Available at: https://www.w3.org/TR/xquery/. Accessed June 1, 2016

38 Fernández-Breis JT, Maldonado JA, Marcos M, et al. Leveraging electronic healthcare record standards and semantic web technologies for the identification of patient cohorts. J Am Med Inform Assoc 2013;20(e2):e288-e296

39 World Health Organization. Building foundations for eHealth: progress of member states: report of the Global Observatory for eHealth. Geneva: World Health Organization; 2006. Available at: http://apps.who.int/iris/handle/10665/43599

40 Muñoz A, Somolinos R, Pascual M, et al. Proof-of-concept design and development of an EN13606-based electronic health care record service. J Am Med Inform Assoc 2007;14(01):118-129

41 Rinner C, Janzek-Hawlat S, Sibinovic S, Duftschmid G. Semantic validation of standard-based electronic health record documents with W3C XML Schema. Methods Inf Med 2010;49(03):271-280

42 Duftschmid G, Wrba T, Rinner C. Extraction of standardized archetyped data from electronic health record systems based on the entity- attribute-value model. Int J Med Inform Vienna 2010;79(08):585-597

43 Sachdeva S, Bhalla S. Semantic interoperability in standardized electronic health record databases. J Data Inf Qual 2012;3(01):1-37

44 Maldonado JA, Moner D, Bosca D, Fernández JT, Angulo C, Robles M. Semantic upgrade and normalization of existing EHR extracts. Paper presented at: 30th Annual International Conference of the IEEE Engineering in Medicine and Biology Society 2008:14661469

45 Muñoz P, Trigo JD, Martínez I, Muñoz A, Escayola J, García J. The ISO/ EN 13606 standard for the interoperable exchange of electronic health records. J Healthc Eng 2011;2(01). Doi: 10.1260/20402295.2.1.1

46 Pahl C, Zare M, Nilashi M, et al. Role of OpenEHR as an open source solution for the regional modelling of patient data in obstetrics. J Biomed Inform 2015;55:174-187 